\title{
Kearifan pada Lingkungan Hidup dalam Novel-Novel Karya Andrea Hirata (Tinjauan Strukturalisme Genetik)
}

\author{
Andri Wicaksono \\ STKIP PGRI Bandar Lampung
}

\begin{abstract}
Abstrak
Hasil cipta sastra akan selalu berbicara tentang manusia dengan segala permasalahan hidupnya, baik hubungan manusia dengan manusia, manusia dengan lingkungannya maupun manusia dengan penciptanya. Melalui karya sastra, nilai-nilai moral dalam kehidupan meresap menjadi pengetahuan tidak sadar pembaca, menjadi buah pikiran, dan emosi pembaca. Emosi pada kelanjutannya melahirkan tindakan; tindakan yang dilakukan berulang-ulang akan membentuk karakter. Dalam kajian ini akan difokuskan pada hubungan manusia dengan lingkungan/alam yang secara spesifik termasuk dalam ajaran nilai dan pendidikan karakter. Yang dikaji sebagai subjek penelitian ini adalah novel-novel karya Andrea Hirata, di antaranya Laskar Pelangi, Sang Pemimpi, dan Padang Bulan. Metode penelitian yang digunakan adalah deskriptif interpretif dengan tinjauan strukturalisme genetik. Unsur nilai dalam hubungan manusia dengan alam meliputi pemanfaatan sumber daya alam, peduli lingkungan, serta menjaga dan melestarikan alam. Karya sastra dan sosiologi tidak hanya menghubungkan manusia dengan lingkungan sosial budaya, tetapi juga dengan alam. Alam Belitong yang indah dengan segala bentuk tipikalnya, ciri dan karakter kedaerahan, warna lokalitas serta kearifan dalam mencintai pesona juga kenestapaannya.
\end{abstract}

Kata kunci: moral, pendidikan karakter, lingkungan hidup, strukturalisme genetik

\begin{abstract}
The scope of literature inventions will always revolves around human beings and all of their problems in life, either it is relationship between humans, humans and their environment or humans and their creators. Through literatures, moral values in life is permeated into unconscious knowledge, thoughts and emotions of the readers. Emotions in its continuation generate actions, and repeated actions define characters. This study focused on relationship between humans and their environment/nature which is specifically included is characters' values and educations. The subject of this research are novels by Andrea Hirata, including Laskar Pelangi, Sang Pemimpi and Padang Bulan. Research method used in this study was descriptive interpretative with genetic structuralism reviews. Elements of values in the relationship between humans and nature included the natural resources utilization, environmental care and nature protection and preservation. Works in the field of literature and sociology were not only connecting people with the socio-cultural environment, but also with nature. The beautiful nature of Belitong with every form of its typical regional traits and characteristics, varieties of localities and locale wisdoms were meticulously described in the effort of embracing nature's enchantment and infliction.
\end{abstract}

Keywords: moral, character building, environment, genetic structuralism 


\section{Pendahuluan}

Sebuah karya sastra ditulis oleh pengarang, antara lain untuk menawarkan model kehidupan yang ideal menurut pengarang. Karya sastra mengandung penerapan moral dalam sikap dan tingkah laku para tokoh sesuai dengan pandangan tentang moral. Melalui cerita, sikap, dan tingkah laku tokoh-tokoh itulah pembaca diharapkan dapat mengambil hikmah dari pesan-pesan moral yang disampaikan. Nilai moral tidak selalu diperlihatkan secara langsung kepada pembaca. Pembaca berusaha mencari sendiri nilai moral yang terdapat dalam karya sastra tersebut.

Sebuah narasi atau cerita tertentu menggambarkan struktur moral kehidupan seseorang atau individu itu sangat kompleks, juga dapat merupakan hubungan berbagai faktor yang di dalamnya menjelaskan bagaimana perkembangan moral dalam kehidupan. Teori respon pembaca menggambarkan bahwa aktivitas yang dilakukan pembaca dapat menghasilkan banyak hal (Haerudin, 2014: 4-5). Pembaca dengan sendirinya akan menyelidiki dan memperkaya apa yang telah ada pada dirinya, baik perasaan dan emosinya maupun pemandangan tentang kehidupan lainnya yang tidak dimilikinya. Menurut Taine (dalam Fananie, 2000: 116-117), sastra tidak hanya sekadar karya yang bersifat imajinatif dan pribadi, tetapi dapat pula merupakan cerminan atau rekaman budaya, suatu perwujudan pikiran tertentu pada saat karya itu dilahirkan. Fenomena hubungan tersebut kemudian dikembangkan oleh Lucien Goldmann yang dikenal dengan Strukturalisme Genetik (Junus, 1985: 20).

Pendekatan strukturalisme genetik di sini digunakan untuk mengkaji beberapa karya Andrea Hirata yang diambil secara acak, terdiri dari novel Laskar Pelangi, Sang Pemimpi, dan Padang Bulan. Adapun yang menjadi tujuan kajian ini adalah untuk mendeskripsikan, 1) kearifan pada lingkungan hidup dalam novel, meliputi pemanfaatan sumber daya alam, peduli lingkungan serta menjaga dan melestarikan alam; 2) pandangan dunia pengarang; dan 3) struktur sosial-budaya masyarakat dalam novel-novel karya Andrea Hirata.

Novel sebagai karya sastra menawarkan pesan moral yang berhubungan dengan sifat-sifat luhur kemanusiaan, memperjuangkan hak dan martabat manusia. Nilai moral itu pada hakikatnya merupakan sarana atau petunjuk agar pembaca memberikan respon atau mengikuti pandangan pengarang. Nilai moral yang dapat diterima pembaca umumnya yang bersifat universal, dalam arti tidak menyimpang dari kebenaran dan hak kemanusiaan. Nilai moral sastra lebih memberatkan pada sifat kodrati manusia yang hakiki, bukan pada aturanaturan yang dibuat, ditentukan, dihakimi manusia (Nurgiyantoro, 2009: 321-322). Lebih lanjut, Nurgiyantoro membagi kriteria 
atau jenis ajaran moral dalam karya sastra mencakup masalah yang bisa dikaitkan bersifat tak terbatas. Secara garis besar jenis ajaran moral dapat dibedakan menjadi tiga macam, yaitu (1) moral yang mencakup hubungan manusia dengan diri sendiri; (2) moral yang mencakup hubungan manusia dengan manusia lain dalam lingkup sosial termasuk hubungannya dengan lingkungan alam; dan (3) moral yang mencakup hubungan manusia dengan Tuhannya.

Kajian ini difokuskan pada ajaran moral manusia hubungannya dengan lingkungan alam. Manusia mempunyai tugas dan kewajiban terhadap alam semesta yaitu menjaga dan melestarikan semua sumber alam untuk menghindari semua bencana yang disebabkan kecerobohan serta dapat mendapatkan alam semesta dalam alam kehidupan dengan memperhatikan agar dapat berjalan menurut kodratnya. Nilai moral yang terkandung dalam hubungan manusia dengan alam meliputi pemanfaatan sumber daya alam, menjaga dan melestarikan alam.

Selanjutnya, berbicara mengenai pendidikan karakter, Lickona (1991: 50-52) memandang karakter memiliki tiga unsur yang saling berkaitan, yakni moral knowing, moral feeling, dan moral behavior. Adapun menurut Suyanto (2010), karakter adalah cara berpikir dan berperilaku yang menjadi ciri khas tiap individu untuk hidup bekerja sama dalam lingkungan keluarga, masyarakat, bangsa dan negara. Dalam pembinaan karakter manusia seutuhnya senantiasa mempertimbangkan bahwa perkembangan moral berkaitan dengan aturan dan konvensi tentang apa yang seharusnya dilakukan manusia dalam interaksinya dengan orang lain (Santrock, 1995: 286-287)

Selanjutnya, Hasan (2010: 9-10) membagi pendidikan karakter menjadi 18 jenis, yaitu religius, jujur, toleransi, disiplin, kerja keras, kreatif, mandiri, demokratis, rasa ingin tahu, semangat kebangsaan, cinta tanah air, menghargai prestasi, bersahabat/ komunikatif, cinta damai, gemar membaca, peduli lingkungan, peduli sosial, dan tanggung jawab. Dalam penelitian ini nilai pendidikan karakter yang akan dikaji adalah karakter ke-16, yaitu peduli lingkungan.

\section{Metode Penelitian}

Metode penelitian yang digunakan adalah deskriptif interpretatif dengan tinjauan strukturalisme genetik. Novel yang dikaji sebagai subjek penelitian ini adalah novel-novel karya Andrea Hirata, di antaranya Laskar Pelangi, Sang Pemimpi, dan Padang Bulan. Kajian ini menggunakan teknik analisis isi (content analysis). Analisis isi merupakan teknik penelitian yang memanfaatkan seperangkat prosedur untuk menarik kesimpulan. Analisis ini juga dapat sebagai metode yang lengkap dan dapat 
direplikasikan untuk membuat kesimpulan spesifik teks (Mayring, 2000: 14). Langkahlangkah yang dilakukan peneliti adalah pengumpulan data, reduksi data, verifikasi data, dan simpulan penelitian.

\section{Pembahasan}

\section{Kearifan pada Lingkungan Hidup}

Lingkungan (milieu) merupakan sesuatu yang melingkupi suatu tubuh yang hidup, seperti tumbuh-tumbuhan, keadaan tanah, udara, pergaulan manusia hidup selalu berhubungan dengan manusia lainnya atau juga dengan alam sekitar. Itulah sebabnya manusia harus bergaul dan dalam pergaulan itu saling mempengaruhi pikiran, sifat, dan tingkah laku. Lingkungan merupakan faktor yang mempengaruhi dan menentukan tingkah laku manusia. Manusia yang hidup dalam lingkungan, baik secara langsung atau tidak, dapat membentuk kepribadian menjadi baik.

Kami adalah 10 umpan nasib dan kami seumpama kerangkerang halus yang melekat erat satu sama lain dihantam deburan ilmu. Kami seperti anak-anak bebek. Tak terpisahkan dalam susah dan senang, (Hirata, 2005: 85).

Sepuluh anggota Laskar Pelangi mengejar pendidikan tanpa rasa putus asa walaupun miskin, semangat yang mereka miliki tidak pernah padam. Kisah persahabatan di atas menyatakan mereka akan selalu bersama, baik dalam keadaan susah maupun senang.

...tragedi atau drama semacam opera sabun tak pernah terjadi di sekolah Muhammadiyah. Sekolah itu demikian teduh dalam kiprahnya, tenang dalam kesahajaannya, bermartabat dalam kesederhanaannya, dan tenteram dalam kemiskinannya, (Hirata, 2005: 374).

Kutipan di atas, menunjukkan adanya persepsi tentang sekolah yang telah meneduhkan jiwa mereka menjadi tenang, bermartabat dalam kesederhanaan, dan tenteram dalam kemiskinan. Sebuah pertunjukan drama kehidupan demi perjuangan pendidikan yang dilakukan oleh anak-anak Laskar Pelangi. Sekolah yang sederhana, murid yang sederhana, dan guru yang tidak pernah lelah mencerdaskan muridmuridnya.

Sampai pada akhirnya, sepuluh anggota Laskar Pelangi berkurang Lintang. Dia memilih keluar dari sekolah setelah ayahnya meninggal tepat empat bulan sebelum ia menyelesaikan SMP. Sahabatsahabatnya merasa amat pedih karena seorang anak yang super jenius, penduduk asli sebuah pulau terkaya di Indonesia harus berhenti sekolah karena kekurangan biaya. Dadaku sesak menahankan 
pemandangan itu. Sore itu adalah sore yang paling sendu di seantero Belitong, dari muara Sungai Lenggang sampai ke pesisir Pangkalan Punai, dari Jembatan Mirang sampai ke Tanjong Pandan. Itu adalah sore yang paling sendu di seantero jagad alam. Saat itu aku menyadari bahwa kami sesungguhnya adalah kumpulan persaudaran cahaya dan api... Kami adalah lapisan-lapisan pelangi terindah yang pernah diciptakan Tuhan. (Hirata, 2005: 405)

Sekolah, kawan-kawan, buku, dan pelajaran adalah segala-galanya bagi Lintang. Itulah dunianya dan seluruh kecintaannya. Alam pun turut bersedih dengan keadaan itu. Unggas yang biasanya riuh rendah di pohon filicium, sore itu lengang. Semua hati terendam air mata melepas sang mutiara ilmu dari lingkaran pendidikan. Lintang, bagi seluruh anggota Laskar Pelangi, adalah mercusuar. Ia bintang petunjuk bagi pelaut di samudra. Begitu banyak energi positif, keceriaan, dan daya hidup terpancar dari dirinya. Ia telah menyihir kepercayaan diri, berani bermimpi melawan nasib, berani memiliki cita-cita.

Contoh lain dalam novel Padang Bulan, kearifan pada lingkungan, yaitu museum, museum paling hebat dan tidak ada yang bisa menandinginya karena selain museum, sekaligus kebun binatang.
Baiklah, mari bicara soal
museum. Di sana ada
sebuah ruangan yang jika
dimasuki harus membuka
sandal dan mengucapkan
Assalamualaikum, demi
menghormati tombak-
tombak karatan, para
peninggalan hulubalang
antah berantah. Uang
kecil yang diselipkan ke
dalam kotak di samping
tombak-tombak itu dapat
menyebabkan pendermanya
awet muda dan enteng jodoh.
Anak-anak yang tak sengaja
menunjuk tombak itu harus
menghisap telunjuknya, agar
tidak kualat (Hirata, .2010 :

17)

Kutipan di atas menunjukkan kearifan masyarakat Melayu yang percaya dengan mitos dan takhayul. Melepaskan sandal dan mengucapkan salam saat memasuki tempat tertentu merupakan suatu penghormatan dan kesopanan yang dibungkus oleh mitos. Penghormatan terhadap benda-benda kuno dan kepercayaan persembahan untuk awet muda sangat berkaitan erat dengan kepercayaan masyarakat.

\section{a. Pemanfaatan Sumber Daya Alam}

Seperti halnya sebuah novel, di dalamnya mengisyaratkan suatu ajaran untuk dibaca, dimengerti, dipahami, dan dapat diimplementasikan dalam kehidupannya. Begitu juga suatu nilai (moral) dalam sastra kaitannya dengan pemanfaatan kekayaan alam, baik hayati maupun non-hayati. Tentu 
saja hal tersebut mengajak kita pembaca untuk dapat sadar dan menyadari apa yang terjadi dan apa yang idealnya dapat dihindarkan dan mensyukuri anugerah yang diberikan Tuhan kepada umat manusia.

"Tuhan memberkahi Belitong dengan timah bukan agar kapal yang berlayar ke pulau itu tidak menyimpang ke Laut Cina Selatan... Adakah mereka telah semena-mena pada rezeki Tuhan...

Eksploitasi timah besarbesaran secara nonstop diterangi ribuan lampu dengan energi jutaan kilo watt...sendiri, kecil, bersinar, indah, dan kaya raya", (Hirata, 2005: 33-34).

Pulau Belitong seperti diungkap dalam kutipan di atas adalah penghasil timah terbesar di Indonesia sejak masa penjajahan Belanda. Setelah merdeka, diambil alih oleh PN Timah dan menyerap hampir seluruh angkatan kerja di Belitong. Lahan eksploitasinya tak terbatas. Sumber daya alamnya dieksploitasi habis-habisan. Sebagian komunitas di Belitong juga termarginalkan dalam ketidakadilan, persamaan kesempatan, dan kesemenamenaan. Begitu juga yang terjadi dalam novel Padang Bulan.

Sisa dari yang tersisa, hanyalah timah buruk yang terlipat amat dalam di bawah tanah. Bulir demi bulir timah itu ditambang penduduk asli dengan pacul, didulang dengan tangan, dan dengan satu sikap dipaksa rela oleh kemiskinan untuk terkubur hidup-hidup. (Hirata, 2010: 23).

Kutipan di atas menggambarkan para penguasa tambang, yaitu pemerintah yang mengelola pertambangan tanpa mempedulikan kesejahteraan masyarakat. Setelah timah habis ditambang, tambang ditinggalkan, diabaikan begitu saja dan berbahaya bagi lingkungan. Yang tersisa hanyalah timah dengan kualitas buruk dan dalam yang ditambang oleh penduduk dengan peralatan sederhana. Kemiskinan telah mengakibatkan penduduk lokal bekerja sebagai pendulang dengan risiko kecelakaan kerja, bahkan risiko kematian yang tinggi. Pemanfaatan alam yang positif dapat dilihat dalam kutipan berikut.

Bendungan itu tak jauh dari rumah mereka. Dulu dipakai Belanda untuk membendung aliran anak-anak Sungai Linggang agar kapal keruk dapat beroperasi... seperti mereka dulu sering bertemu. (Hirata, 2010: 1).

Dari kutipan di atas digambarkan manfaat bendungan yang dipakai Belanda untuk membendung Sungai Linggang sekaligus tempat bagi Syalimah dan Zamzami dulu sering bertemu.

\section{b. Menjaga dan Melestarikan Alam}

Manusia mempunyai tugas dan kewajiban terhadap alam semesta, yaitu menjaga dan melestarikan semua sumber 
alam untuk menghindari bencana yang disebabkan kecerobohan.

Tuhan

memberkahi

Belitong dengan timah-

timah dialirkan-Nya ke sana untuk menjadi mercusuar bagi penduduk pulau itu sendiri. Adakah mereka telah semena-mena pada rezeki Tuhan sehingga nanti terlunta-lunta seperti di kala Tuhan menguji bangsa Lemuria. (Hirata, 2005: 34) Ajaran kuno turun-temurun di Belitong agar masyarakat tidak semena-mena memperlakukan hutan dan sumber-sumber air. Ajaran itu mengandung tenaga sugestif ketakutan terhadap kualat. . (Hirata, 2005: 362)

Contoh lainnya dapat ditemui dalam novel Sang Pemimpi, ketika Ikal dan Arai meninggalkan Belitong untuk ke Jawa. Melalui deskripsi imaji visual tokoh Ikal digambarkan Pulau Belitong yang porak-poranda karena kerakusan manusia, kerakusan penjajah, dan PN Timah pada masanya. Pulau Belitong yang kaya akan timah seharusnya dapat dijaga kelestariannya dan dapat dimanfaatkan hasil buminya dengan arif dan bijaksana.

Kami membahas kerusakan lingkungan karena ulah PN Timah dan jumlah ganti rugi yang akan kami tuntut karena tanah ulayat kami rusak berantakan. (Hirata, 2006: 47)

Kupandangi pulau kecilku yang porak- poranda karena kerakusan manusia. (Hirata, 2006: 208)

\section{c. Peduli Lingkungan}

Peduli lingkungan merupakan salah satu nilai dari 18 nilai dalam pendidikan karakter. Kepedulian terhadap lingkungan ditunjukkan oleh Tokoh Aku dan Arai, simulasi yang dilakukan melalui telefon dari kaleng susu dalam novel Sang Pemimpi. Mereka menuntut ganti rugi kepada PN Timah karena kerusakan lingkungan juga kompensasi beban psikologis bagi penduduk Belitong yang terkena imbas eksploitasi PN Timah.

“Tiga miliar untuk air minum yang tercemar phyrite, empat miliar untuk risiko kontaminasi radio aktif, tujuh miliar kompensasi beban psikologis karena kesenjangan sosial, dan dua miliar untuk hancurnya habitat pelanduk," usul Arai berapi-api. (Hirata, 2006: 47)

Masih bagian novel Sang Pemimpi, Ikal merasakan kepedulian pada tanah tumpah darahnya, yaitu kerinduan terhadap keindahan alam Belitung.

Pulau Belitong tumpah darahku, terapung-apung tegar, tak pernah lindap diganyang ombak dua samudra nan bergelora. Belitung yang kukuh tak terkalahkan, kapankah aku melihatmu (Hirata, 2006: 207). 
Pulau Belitong yang kokoh terapung tegar di tengah lautan diganyang ombak dua samudra. Belitong yang kukuh tak terkalahkan telah dirindukan oleh Ikal yang baru saja berangkat dari Belitong untuk memperbaiki nasib di Jawa, kuliah. Kepedulian terhadap lingkungan juga mewujud dalam kutipan berikut.

WC ini sudah hampir setahun diabaikan karena kran air yang mampet. Tapi manusia-manusia cacing, para intelektual muda SMA Negeri yang tempurung otaknya telah pindah ke dengkul, nekat menggunakannya jika panggilan alam itu tak tertahankan... Dan kamilah yang menanggung semua kebejadan moral mereka (Hirata, 2006: 127).

WC yang mampet seharusnya sudah tidak dipakai lagi, apapun alasannya. Tapi, siswa SMA yang "moralnya bejad" tetap nekat menggunakannya meskipun sudah rusak. Ikal, Jimbron, dan Arai dihukum membersihkan WC tersebut sebagai orang yang menanggung penderitaan dari apa yang dilakukan orang lain, "intelektual muda SMA Negeri yang tempurung otaknya telah pindah ke dengkul."

Kepedulian terhadap lingkungan berikutnya terdapat dalam novel Padang Bulan, yakni kepedulian tentang turunnya hujan pertama ketika menyongsong musim penghujan.

...kalau hujan pertama musim hujan turun pas pada 23 Oktober, dan sore, pasti kampungku akan tampak lebih memesona... (Hirata, 2010: 31)

...ia akan mengguyur dengan teratur, usai asar biasanya, lembut, berkawan, dan adakalanya syahdu. (Hirata, 2010: 32)

Aku, alam, dan hujan pertama, telah membentuk semacam persengkokolan, yang begitu ganjil... (Hirata, 2010: 34)

Ikal mempunyai teori yang konyol sehingga tidak pernah dikisahkan pada siapa pun dan telah menjadi rahasia sejak masa kecilnya. Kepedulian Ikal pada awal hujan pada 23 Oktober sore membuat delima, angsana, kemang, dan kecapi akan memucuk bersama, kemudian jamur tiong yang indah dan dapat dimakan akan subur, bunga bakung bersemi awal sepanjang musim hujan itu.

\section{Pandangan Dunia Pengarang}

Andrea Hirata merupakan penulis yang mampu menggugah dunia kesusastraan Indonesia dewasa ini. Karya-karya Andrea Hirata selalu menyampaikan cerita dalam kehidupan yang penuh problema ekonomi, masa depan, cita-cita, bahkan sampai cerita cintanya. Semua novel Andrea Hirata mempunyai cerita yang saling berhubungan, mulai dari tetralogi Laskar Pelangi, dwilogi Padang Bulan dan Cinta Dalam Gelas, dan novel Sebelas Patriot serta yang terbaru, Ayah. Semua berkisah tentang perjuangan, pendidikan, dan cinta, selain tema tersebut Andrea Hirata selalu mengungkapkan keindahan pulau Belitong lewat novel- 
novelnya.

Pengarang ingin menyampaikan pandangannya atau pandangan kelompoknya terkait pendidikan, cita-cita, kehidupan perekonomian, serta kisah cinta. Karya pertamanya yang berjudul Laskar Pelangi merupakan novel best seller di Indonesia. Tema yang diangkat dalam novel Laskar Pelangiadalahkehidupansehari-haridisekitar penulis, mulai dari sulitnya mendapatkan pendidikan, sampai dengan usah anya meraih cita-cita. Sebuah perjuangan di dalam dunia pendidikan serta kegigihan dalam menjalani hidup dia kisahkan dengan bahasa yang memikat dalam novelnya, Laskar Pelangi. Seperti yang diceritakan dalam novel, Lintang harus bersepeda menempuh jarak 80 kilometer setiap hari untuk bisa bersekolah. Sekolah para anggota Laskar Pelangi pun sungguh memprihatinkan.

Adapun sekolah ini, SD Muhammadiyah, juga sekolah kampung yang paling miskin di Belitong. (Hirata, 2005: 4).

Tokoh-tokoh yang diceritakan pengarang tidak sedikit pun mengeluh akan hal itu. Mereka tetap bersemangat demi mendapatkan pendidikan. Lewat novelnovelnya pengarang ingin menyampaikan pikiran tentang perjuangan untuk mendapatkan pendidikan. Begitu juga dalam novel Padang Bulan, dalam novel tersebut Andrea Hirata menceritakan kembali tema perjuangan pendidikan lewat tokoh Enong yang harus bekerja keras sebagai tulang punggung keluarga di samping ia juga berkeinginan menjadi seorang guru bahasa Inggris. Enong tetap menyempatkan belajar bahasa Inggris di sela-sela waktu bekerja sebagai pendulang timah. Bagi Enong, pendidikan adalah segalanya.

Dalam kehidupan nyata, pengarang juga mempunyai karakter yang pantang menyerah dalam segala hal. Pengarang sempat merantau ke Jawa untuk berkelana mempertaruhkan nasib. Andrea Hirata merupakan sosok pekerja keras dengan jiwa patriotisme yang sangat luar biasa. Andrea ingin sekali membahagiakan orang tuanya dengan karya-karyanya. Andrea Hirata juga merupakan sosok yang religious, semua novelnya tidak keluar dari ajaran agamanya, Islam. Dengan penceritaan tokoh Ikal dalam seluruh novelnya (kecuali Ayah) dan latar belakang Belitong, Andrea Hirata menampilkan ajaran agama, moral, dan sosial dengan maksimal. Ia juga berpandangan bahwa mimpi itu harus dicapai, dan jangan takut untuk bermimpi. Semangat untuk menggapai mimpi seolah menjadi pesan utama dari semua novelnya. Pandangan Andrea Hirata untuk jangan takut bermimpi sangat jelas dicurahkan pada novel Sang Pemimpi. Novel ini adalah sebuah kisah kehidupan yang memesona dan akan membuat seluruh pembaca percaya pada 
kekuatan mimpi dan pengorbanan. Kekuatan mimpi itu tampak pada kutipan berikut

...cita-cita kami adalah kami ingin sekolah ke Prancis! Ingin menginjakkan kaki di altar suci almamater Sorbonne, ingin menjelajah Eropa sampai ke Afrika. (Hirata, 2006: 73).

Dari kutipan-kutipan teks dalam novel Sang Pemimpi itu jelas sekali pengarang berpandangan bahwa impian itu harus ada dan harus diperjuangkan. Begitulah pandangan dunia pengarang mengenai pentingnya pendidikan, impian, dan cara memperjuangkannya. Terlihat jelas sekali bahwa novel-novel Andrea Hirata selalu berkisah tentang motivasi untuk menggapai mimpi mungkin karena itu novel Andrea Hirata sering dikatakan sebagai novel inspirasi dan motivasi.

Andrea Hirata juga merupakan sosok yang humanis. Solidaritasnya dengan sesama sangat tinggi. Dalam novel Padang Bulan diceritakan jiwa humanisnya dalam tokoh Ikal yang bersahabat dengan Detektif M. Nur dan Enong. Persahabatan mereka sangat harmonis dan saling memahami. Andrea Hirata juga sering menceritakan kisah cintanya dalam novel-novelnya. Dalam hal ini pengarang berpandangan bahwa cinta juga butuh pengorbanan dan harus diperjuangkan. Dalam novel Laskar Pelangi pengarang sedikit menceritakan kisah cintanya saat bertemu dengan A Ling untuk pertama kalinya. Kisah cinta itu berkelanjutan sampai Ikal memberanikan menemui A Ling sendirian. Ikal meminta bantuan temannya untuk mempertemukannya dengan A Ling, gadis Tionghoa yang dia kagumi.

$$
\text { Perjuangan cinta Ikal tersebut }
$$
merupakan pandangan pengarang terhadap cinta, bahwa cinta memang butuh pengorbanan dan harus diperjuangkan serta dijaga. Kesetiaan Ikal tersebut sejalan dengan pribadi pengarang yang sangat mengagungkan cinta, setia terhadap cinta. Andrea Hirata itu sangat mengagungkan cinta dan tipe orang yang setia. Andrea Hirata merupakan sosok pemuda sederhana yang cerdas dan setia pada obsesinya, A Ling. Dalam novel Padang Bulan, tokoh Ikal rela melakukan apapun demi cintanya, berikut kutipannya
Aku, hanya perlu menjadi seorang pelayan warung kopi, demi seseorang yang paling kuinginkan di muka bumi ini melebihi apapun. Maka, pengorbananku belumlah seberapa dan aku tetap menjadi pahlawan bagi cinta pertamaku. (Hirata, 2010: 154).

Berbagai rencana dirancang Ikal dengan tujuan agar A Ling kembali bertengger di boncengan sepeda Ikal. Dia 
tidak bisa melihat Zinar tanpa cemburu, tak dapat melihat A Ling tanpa patah hati, tak dapat melihat ibunya tanpa rasa malu, tak dapat melihat ayahnya tanpa perasaan bersalah. Begitulah gambaran cerita cinta dari pengarang. Dalam hal ini pengarang mempunyai karakter setia pada cintanya dan ingin menyampaikan pandangannya bahwa cinta harus diperjuangkan dan butuh pengorbanan. Pengorbanan yang digambarkan Andrea Hirata melalui tokoh Ikal sungguh luar biasa.

\section{Struktur Sosial-Budaya Masyarakat} Belitong dalam Novel Andrea Hirata

Latar belakang sosial budaya yang ditampikan oleh Andrea Hirata dalam novel-novelnya sebagian besar dan bisa jadi mendominasi adalah sebuah kehidupan masyarakat yang ada di Belitong, dengan kesederhanaan masyarakat dan heterogennya suku bangsa yang tinggal. Masyarakat dalam novel ini dikisahkan sebagai masyarakat yang miskin, penuh dengan keterbatasan ekonomi.

Seperti dalam Laskar Pelangi dan sang Pemimpi, jika dilihat dari kebiasaan hidup para pelaku utama cerita dalam masyarakat Belitong, di mana masyarakat yang melingkupi para tokoh adalah para buruh yang bekerja di tambang timah milik PN Timah. Mereka hidup di bawah garis kemiskinan. Mereka mayoritas hidup sebagai buruh kasar di PN Timah, tak terkecuali orang tua anggota Laskar Pelangi. Karena orang tua mereka bekerja sebagai buruh kasar di PN Timah, kebiasaan dan pola hidupnya pun banyak dipengaruhi oleh aturan-aturan yang berlaku dalam perusahaan itu. Selain itu, anggota Laskar Pelangi juga punya kebiasaan tersendiri.

\section{Karena kegemaran kolektif terhadap pelangi maka $\mathrm{Bu}$ Mus menamai kelompok kami Laskar Pelangi (Hirata, 2005: 150)}

Mereka punya kebiasaan unik, yaitu suka menyaksikan pelangi secara beramairamai dengan memanjat pohon filicium ${ }^{1}$ setelah hari hujan sambil melihat pelangi. Karena kebiasaan unik ini, oleh guru mereka, $\mathrm{Bu}$ Mus, mereka diberi julukan "Laskar Pelangi”.

Masyarakat Belitong kebanyakan berasal dari suku Melayu, Sawang, dan keturunan Cina (Hokian). Karena ada berbagai suku bangsa yang tinggal di Belitong, percampuran budaya tidak terhindarkan, baik itu adat istiadat/kepercayaan, sikap hidup, dan bahasa yang dipakai. Adat istiadat Melayu

$1 \quad$ Kerai payung (Filicium decipiens) atau ki sabun adalah spesies tanaman dalam suku leraklerakan (Sapindaceae). Tumbuhan ini berasal dari Asia tropis dan Afrika, yaitu: Ethiopia, Kenya, Tanzania, Malawi, Mozambique, Zimbabwe, India, dan Srilanka. Saat ini kerai payung telah tersebar di berbagai daerah, terutama daerah tropis termasuk di Indonesia.

Sumber: Filicium decipiens (Wight \& Arn.) Thwaites (pdf). Informasi Singkat Benih No.137, Nopember 2012. Balai Perbenihan Tanaman Hutan (BPTH) Sulawesi. Diakses pada tanggal 23 April 2014) 
terlihat pada kegemaran masyarakatnya pada irama semenanjung, dentuman rebana, dan pantun yang sambut-menyambut.

Jumlah orang Tionghoa

di kampung kami sekitar

sepertiga dari total populasi...

Komunitas ini selalu tipikal:

rendah hati dan pekerja

keras. Meskipun jauh

terpisah dari akar budayanya

namun mereka senantiasa

memelihara adat istiadatnya.

(Hirata, 2005: 31)

Mengenai kepercayaan, masyarakat

Pulau Belitong percaya terhadap seekor burung yang disebut burung Pelintang Pulau. Menurut kepercayaan masyarakat ini, apabila burung Pelintang Pulau singgah di kampung mereka, maka di tengah laut sedang terjadi badai atau angin puting beliung yang ganas. Kepercayaan lain yang juga tumbuh di Belitong adalah tentang adanya penganut ilmu buaya. Menurut kepercayaan masyarakat Belitong, apabila mati para penganut ilmu buaya akan menjadi buaya. Salah satu penganut ilmu ini adalah Bodenga dan ayahnya.

Selain itu, masyarakat Belitong juga mempercayai adanya seorang dukun yang sakti mandraguna, yang dipercaya bisa mengabulkan permintaan apa saja dan dapat dimintai petunjuk. Dalam cerita ini sang dukun bernama Tuk Bayan Tula yang hidup di pulau terpencil di Belitong, yakni di pulau
Lanun. Selain adat istiadat Melayu, ada juga adat istiadat Tionghoa yang mewarnai novel ini, yaitu sebagaimana terlihat dalam peristiwa perjumpaan Ikal dan A Ling pada waktu upacara sembahyang rebut atau Chiong Si Ku di Kelenteng.

Selanjutnya, masalah sosial budaya yang diceritakan dalam novel Padang Bulan adalah masalah masyarakat Melayu. Diceritakan bahwa tipikal orang Melayu yang suka mencibir, mencemooh, menjelekjelekkan pemerintah, mengobrol lama di warung kopi sehingga seringkali dianggap sebagai bangsa yang pemalas karena terlalu senang membuang-buang waktu di warung kopi dan banyak berkomentar. Kegemaran bermain catur berkaitan erat dengan kegemaran orang Melayu yang lain, yaitu minum kopi di warung kopi. Catur dan warung kopi adalah dua hal yang tidak bisa dipisahkan.

Menjadi juara catur adalah
idaman setiap lelaki Melayu
sebab gengsinya tinggi dan
hadiahnya besar. Jika jadi juara
catur, paling tidak membual di
warung-warung kopi, didengar
orang, hal itu juga kegemaran
orang Melayu (Hirata, 2010:
116)

Juara catur menjadi hal yang sangat prestisius dan memiliki nilai yang tinggi di mata masyarakat. Kebanggaan seorang juara catur adalah ketika ia berkunjung ke warung 
kopi. Saat di warung kopi ia akan terlibat pembicaraan dengan orang lain. Kutipan di atas menunjukkan kegemaran orang Melayu yang lain, yaitu saat terlibat dalam pembicaraan yang seringkali disertai dengan membual. Berikut ini adalah kutipan yang menunjukkan kebiasaan hidup, adat istiadat, keyakinan, pandangan hidup, cara berpikir, cara bersikap, dan tradisi budaya Melayu.

Yahnong, singkatan untuk ayah bagi anak tertua mereka, Enong. Kebiasaan orang Melayu menyatakan sayang pada anak tertua dengan menggabungkan nama ayah dan nama anak tertua itu (Hirata, 2010: 2).

Kutipan di atas menunjukkan kebiasaan masyarakat Melayu dalam menggabungkan nama ayah dan nama anak tertua. Yahnong merupakan gabungan kata dari ayah dan Enong. Yahnong bermakna ayah dari Enong. Kebiasaan ini menunjukkan rasa sayang kepada anak tertua. Lalu, ada pula kebiasaan lain yang unik. Anak muda sering dipanggil Boi.

Ini tak ada hubungannya dengan Boy dalam bahasa Inggris sebab anak perempuan pun sering dipanggil Boi (Hirata, 2010: 10).

Kutipan di atas menjelaskan tentang kebiasaan masyarakat Melayu yang memanggil anak muda dengan sebutan boi. Sebutan ini sama sekali tidak ada hubungannya dengan panggilan kepada anak laki-laki dalam bahasa Inggris. Kutipan di atas menjelaskan mengenai panggilan Enong yang secara khusus Zamzani berikan kepada anak perempuannya, yaitu Enong. Selain menggabungkan nama ayah dan nama anak tertua, orang Melayu biasa menamai anak dengan bunyi senada seirama.

Jika nama anak tertua Murad, misalnya, tujuh orang adik di bawahnya adalah Munzir, Munaf, Munir, Muntaha, Munawaroh, Mun'im, dan Munmun (Hirata, 2010: 9)

Kutipan di atas menunjukkan kebiasaan unik masyarakat Melayu yang menamai anak-anak mereka dengan bunyi yang senada dan seirama. Keluarga Melayu udik biasanya memiliki banyak anak. Dari anak yang banyak itu nama mereka dibuat senada dan seirama. Dalam kutipan di atas dicontohkan nama anak yang semuanya berawalan suku kata $m u$-.

Dari gerakan berikutnya, kulihat ibu tampaknya mau meraihcentong nasididekatnya dan melempar kepalaku, tapi dalam detik yang kritis itu, ia dapat mengendalikan emosi. Mungkin ia teringat akan kepercayaan kuno masyarakat Melayu.... (Hirata, 2010: 148).

Kutipan di atas terjadi saat Ikal batal berangkat ke Jakarta karena masih ingin menyelesaikan permasalahan cintanya. Sang 
ibu yang kesal akan perilaku Ikal hampir saja saja memukul Ikal dengan centong nasi atau sendok besar yang biasa digunakan untuk mengambil nasi. Namun, ibu Ikal masih bisa mengendalikan diri dan teringat kepercayaan kuno Melayu mengenai pembangkitan di hari kiamat. Kutipan di atas menunjukkan kepercayaan Melayu kuno yang masih dijunjung tinggi oleh masyarakat Melayu.

\section{Lingkungan sosial masyarakat}

Melayu di Belitong Timur sangat heterogen.

Pendeskripsian latar budaya yang begitu akurat sangat membantu pembaca dalam memahami dan membayangkan suasana yang ada pada cerita. Latar sosial ini menggambarkan akulturasi budaya Melayu dengan suku bangsa yang lain, terutama etnis Tionghoa.

Jika sore menjelang, dari
jendela rumah sering
kupandangi bangunan pasar
yang indah dan simetris,
gabungan dua gaya arsitektur.
Lisplang berenda - renda
itu jelas gaya Melayu,
tapi ventilasi dengan cara
melubangi dinding papan
hanya dilakukan orang Khek.
Mengecat rumah dengan ter
hitam juga bukan kebiasaan
orang Melayu, (Hirata, 2010:
241).

Kutipan di atas menunjukkan akulturasi antara budaya Melayu dan budaya Tionghoa dalam hal arsitektur bangunan. Akulturasi ini menghasilkan bangunan pasar yang indah dan simetris. Akulturasi budaya menghasilkan bangunan dengan gaya arsitektur yang berbeda. Melalui kutipan di atas dapat dikatakan bahwa masyarakat Melayu adalah masyarakat yang terbuka dan bisa secara berdampingan hidup dengan budaya lain.

"Belum sempat kuambil
ancang-ancang, dua bilah
alis pedang tertarik ke atas.
Perempuan Ho Pho itu merepet
dalam bahasa Khek campur
Melayu" (Hirata, 2010: 243).

Kutipan di atas adalah peristiwa saat A Ling marah kepada Ikal. Dalam kemarahannya, A Ling berbicara dengan cepat. Saat marah itulah A Ling berbicara dengan bahasa Khek, yaitu bahasanya sendiri dan bahasa Melayu, yaitu bahasa tempat tinggalnya. Hal ini menunjukkan adanya akulturasi dari sisi bahasa.

"Perkawinan itu seperti
pertemuan beragam suku
dalam masyarakat kami.
Banyak sekali orang dari suku
bersarung, orang Melayu,
orang Tionghoa sendiri, dan
orang Sawang hadir di sana",
(Hirata, 2010: 249).

\section{Simpulan}

Gambaran keramahan masyarakat Melayu ditunjukkan dengan sikap keterbukaan dan dapat hidup berdampingan dengan masyarakat yang lain tanpa 
menimbulkan gesekan. Kerukunan hidup tampak pada kutipan di atas. Pada saat ada acara perkawinan, orang yang datang ke acara itu berasal dari berbagai suku. Disebutkan, suku yang ada dalam masyarakat Melayu antara lain suku bersarung, orang Melayu, orang Tionghoa, dan orang Sawang.

Akulturasi budaya Melayu dan Tionghoa digambarkan dengan harmonis dan serasi, tanpa benturan yang berarti. Suku Melayu yang mayoritas beragama Islam yang religius, etnis Tionghoa yang beragama Konghucu hidup berdampingan dengan damai. Budaya Melayu dan budaya Tionghoa berjalan beriringan dan saling melengkapi. Masyarakat Melayu di Belitong Timur adalah masyarakat yang heterogen. Terdapat beragam suku dalam masyarakat, yaitu Orang Melayu, Tionghoa, suku bersarung, dan orang Sawang. Sifat orang Melayu yang terbuka telah menyebabkan berbagai budaya dalam masyarakat Melayu mengalami akulturasi yang serasi dan harmonis terutama akulturasi budaya Melayu dan Tionghoa. Akulturasi ini tampak dalam hubungan sosial masyarakat, bahasa, dan seni arsitektur.

\section{Daftar Pustaka}

Fananie, Zaenuddin. 2000. Telaah Sastra. Surakarta: Muhammadiyah University Press.

Haerudin, Dingding. 2014. "Mengkaji Nilai-Nilai Moral Melalui Karya Sastra". Artikel Jurnal Pendidikan Bahasa dan Seni. Bandung: FPBS UPI, 2014.

Hasan, Said Hamid, dkk. 2010. Pengembangan Pendidikan Budaya dan Karakter Bangsa.

Jakarta: Kemdiknas Badan Penelitian dan Pengembangan Pusat kurikulum

Hirata, Andrea. 2005. Laskar Pelangi. Jogyakarta: PT. Bentang Pustaka.

-----------------. 2006. Sang Pemimpi. Jogyakarta: PT. Bentang Pustaka.

2010. Padang Bulan. Jogyakarta: PT. Bentang Pustaka.

Junus, Umar. 1985. Resepsi Sastra Sebuah Pengantar. Jakarta: Gramedia.

Lickona, Thomas. 1991. Educating for Character: How Our School Can Do Teach Respect and Responsibility. New York: Brantam Book.

Mayring, P., 2000. "Qualitative Content Analysis". Qualitative Sozialforschung: Vol. 1 No.2 Juni 2000.

Nurgiyantoro, Burhan. 2010. Teori pengkajian Fiksi. Yogyakarta: GMUP.

Santrock. J.W. 1995. Live Span Development. (Alih bahasa: Achmad Chusairi dan Yuda Damanik). Jakarta: Erlangga.

Suyanto, 2010. "Urgensi Pendidikan Karakter”. kemdiknas.go.id. diunduh pada tanggal 25 Mei 2013 pukul 14.15 WIB. 